\title{
Sawaddee Krub: greetings to the membership in Archives of Plastic Surgery
}

\section{Apirag Chuangsuwanich}

President of the Society of Plastic and Reconstructive Surgeons of Thailand Associate Editor, Archives of Plastic Surgery

Division of Plastic Surgery, Faculty of Medicine Siriraj Hospital, Mahidol University, Bangkok, Thailand

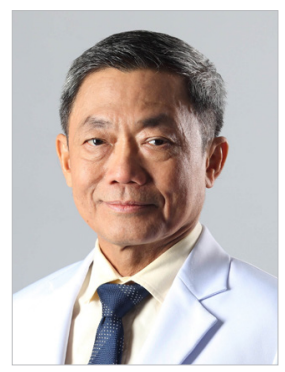

It is truly a privilege of essential importance for Thai plastic surgeons and the Society of Plastic and Reconstructive Surgeons of Thailand (ThPRS) to join the Archives of Plastic Surgery (APS), as this provides us with the opportunity to share and exchange surgical techniques and new innovations, as well as to update surgical knowledge in plastic surgery at the international level, which will be extremely beneficial for our people and patients.

The ThPRS was founded in 1976, and currently has 450 members and nine training centers. Over the years, the ThPRS has held numerous national and international events and congresses, and its members have submitted many manuscripts for presentation at international meetings to exchange and update surgical knowledge in plastic surgery. Being part of APS will serve as a strong motivation for ThPRS members to conduct research, develop new surgical techniques and innovations, and exchange information on notable cases. I strongly believe that this new important role will mark a new page in the history of our society.

In addition, the ThPRS wishes to thank the Korean Society of Plastic and Reconstructive Surgeons and Prof. Joon Pio Hong, the APS Editor-in-Chief, for the kind invitation to join APS, especially during the ongoing global coronavirus disease (COVID-19) pandemic, which has required us all to make tremendous adjustments in plastic surgery throughout the world to cope with it.
On behalf of the ThPRS, we are delighted and honored to be a part of APS, an influential journal in the world of plastic surgery. We look forward to close cooperation and promoting knowledge in plastic surgery for the utmost mutual benefit of our peoples. Thank you.

\section{NOTES}

\section{Conflict of interest}

Apirag Chuangsuwanich is an editorial board member of the journal but was not involved in the peer reviewer selection, evaluation, or decision process of this article. No other potential conflicts of interest relevant to this article were reported.

\section{ORCID}

Apirag Chuangsuwanich

$$
\text { https://orcid.org/0000-0002-3733-9679 }
$$

Correspondence: Apirag Chuangsuwanich

Division of Plastic Surgery, Faculty of Medicine Siriraj Hospital, Mahidol University, 2 Prannok, Bangkoknoi, Bangkok 10700, Thailand

Tel: +66-2-419-8002, Fax: +66-2-412-8109, E-mail: apirag@gmail.com

Received: April 14, $2021 \bullet$ Revised: May 12, $2021 ・$ Accepted: May 13, 2021 pISSN: 2234-6163 • elSSN: 2234-6171

https://doi.org/10.5999/aps.2021.00780 • Arch Plast Surg 2021;48:243 